Portland State University

PDXScholar

$5-28-2018$

\title{
An Environmental Justice Assessment of the Hanford Nuclear Waste Site Cleanup Project
}

Hannah Madden

Portland State University

Follow this and additional works at: https://pdxscholar.library.pdx.edu/honorstheses

Let us know how access to this document benefits you.

\section{Recommended Citation}

Madden, Hannah, "An Environmental Justice Assessment of the Hanford Nuclear Waste Site Cleanup Project" (2018). University Honors Theses. Paper 564.

https://doi.org/10.15760/honors.571

This Thesis is brought to you for free and open access. It has been accepted for inclusion in University Honors Theses by an authorized administrator of PDXScholar. Please contact us if we can make this document more accessible: pdxscholar@pdx.edu. 


\title{
An Environmental Justice Assessment of the Hanford Nuclear Waste Site Cleanup Project
}

\author{
Author \\ Hannah Madden \\ Advisor \\ Jeffrey Gerwing, PhD.
}

Submitted in support of the degree of Bachelor of Science in Environmental Studies

Portland State University Honors College 


\begin{abstract}
Large scale restoration projects are multi-faceted and have many intricate management needs. Environmental justice can often be overlooked and not involved in considerations of these projects, and can be lacking in evaluation methods that provide support for project managers. This paper analyzes the Hanford Nuclear Waste Site Cleanup Project through the lens of an environmental justice rubric with eight separate categories designed to assess the inclusion of all stakeholders in this large scale restoration project. The Hanford Project ended up with a final score of $69 \%$ on the rubric, or a D+, with instances of both excellent and poor environmental justice inclusion over the past 20 years.
\end{abstract}




\section{Table of Contents}

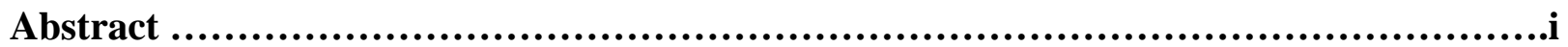

Table of Contents ................................................................................

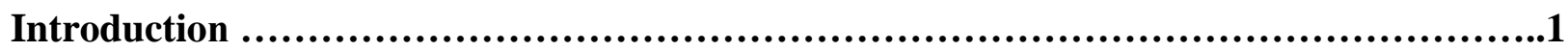

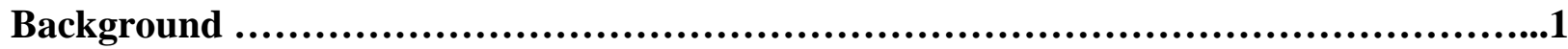

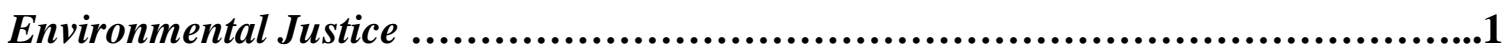

The Hanford Site ....................................................................2

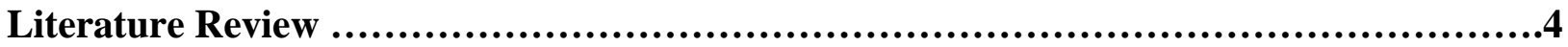

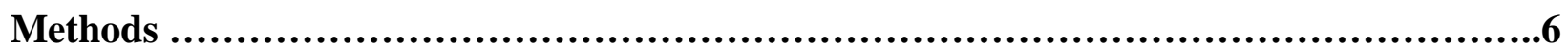

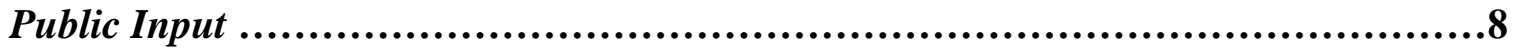

Stakeholder Identification ..............................................................8

Worker Safety ........................................................................

Surrounding Area Wellbeing ........................................................9

Regional Involvement ...............................................................9

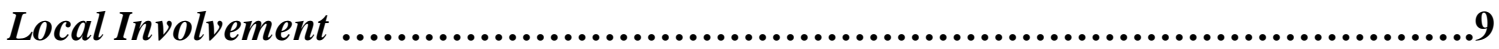

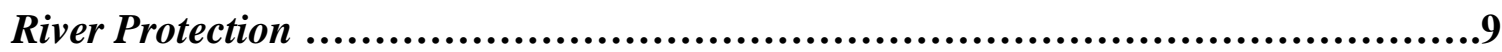

Attempt to Lessen Environmental Impact ..............................................10

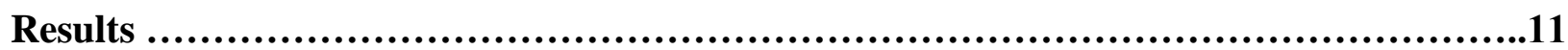

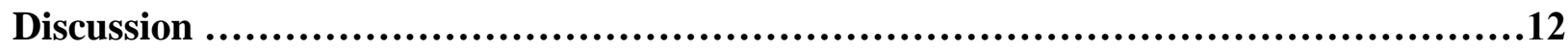

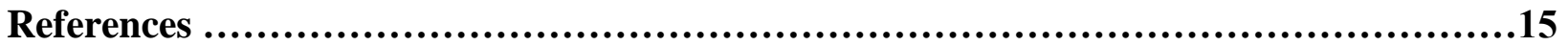




\section{Introduction:}

Mitigation projects have always been important and necessary aspects of civilized society (Hall, 2015). Projects that attempt to return an ecosystem to its historical state have become more common, and they are only increasing in frequency in modern times (Timpane-Padgham et al, 2017). An important aspect of these projects that can often be overlooked is the identification and inclusion of all stakeholders and their opinions, or environmental justice (Foreman, 2002). This is made especially difficult during large scale restoration projects, when stakeholders can span city and state lines and can include non-human elements, like ecosystem services and biological components.

Being able to identify and encompass all groups that will be affected by a project is an important tool that has become emphasized in project planning in recent years (Palamar, 2008). According to the UCLA Luskin School of Public Affairs, frameworks that assess the inclusion of stakeholders in environmental projects can ultimately help to close the gap between restoration managers and the general public (Callahan et al., 2011). Since the passing of Executive Order 12898 in 1996 which mandated that federal agencies are required to consider environmental justice in their policies and programs, many private non-federal companies have been attempting to do the same; however, they are not required to do so by law (Executive Order 12898, 1996). Therefore, using frameworks to analyze environmental projects, especially ones that encompass large expanses of both time and land area, can be helpful in recognizing injustices.

\section{Background:}

Environmental Justice: Environmental justice is a broad, multi-dimensional term that many have attempted to define (Foreman, 2002). The Environmental Protection Agency’s (EPA) definition of environmental justice is just one paragraph, which includes "the fair treatment and 
meaningful involvement of all people regardless of race, color, national origin, or income, with respect to the development, implementation, and enforcement of environmental laws, regulations, and policies.” The EPA further states that this goal is meant for all people and communities of the United States, no matter income, class, or ethnicity. The term "environmental justice" was first coined in the year 1950 during the civil rights movement (Neimanis et al., 2012), meaning it is just under 70 years old. This broad, undefined nature of environmental justice makes it easy for managers of environmental projects to define environmental justice for themselves and believe that they are upholding it, while paying little attention to all of the people that their project may actually be affecting. Some managers of environmental projects create their own guidelines on how to recognize and uphold environmental justice throughout their entire project, but again, they are unregulated and usually not universal (Miller-Travis, 2018). These projects can range from local non-governmental organizations attempting a community science project, or they can span nation-wide, like the EPA's stance on climate change. One such large environmental project that spans state policies as well as non-governmental ones is the Hanford Nuclear Waste Cleanup Project.

The Hanford Site: The Hanford Nuclear Site is located in southeastern Washington State adjacent to the Columbia River. During World War II, the site was built to create nuclear weapons to assist in the war (Hanford.gov, 2017), and later, during the Cold War, Hanford was used to experiment with atomic bombs. After the Cold War ended, the production of plutonium slowed, and the need for a site as large as Hanford diminished. In early 1989, the Hanford site was shut down and was superfund site listed as focus turned to the cleanup of the nuclear waste it had accumulated over the years (Hanford.gov, 2017). Both solid and liquid waste from the production of plutonium has to be removed and safely buried or stored, and reactor buildings and 
auxiliary structures also have to be sterilized and cleaned up. Current technology does not allow for the de-toxifying of hazardous waste, so the most managers can do is store the waste in a nonharmful environment. Currently, the site is managed by three separate departments: the Washington Department of Ecology, the Washington Department of Energy, and the United States Environmental Protection Agency (Hanford.gov, 2017). These three agencies have entered into a tri-party agreement, meaning that they share the responsibility for the cleanup of the site. The Hanford site in particular is an interesting restoration project to put into the context of an environmental justice framework because of the many years that it has been undergoing cleanup. It also has many stakeholders that are invested in the project, whether they are affected directly or indirectly, as well as multiple managers. This paper serves not as a criticism to Hanford directly, but as an in-depth look into how large scale restoration projects can best utilize their resources to incorporate all beings affected by the outcomes and efforts of their actions.

Since the Hanford cleanup project has been going on for such a span of time, a substantial amount of literature has been published by various sources, both critiquing and praising the efforts that have been made over the years. In order to fairly judge Hanford in as little a biased way as possible, the Hanford Advisory Board Reports are the only pieces of work that have been scored using an environmental justice framework. The Hanford Advisory Board has been in action since the late 1990s, making recommendations and overseeing the various cleanup efforts as they came about. The Advisory Board started producing annual reports in 2007, and have continued their efforts each year until 2017, with a brief lapse in reports for the years 2011, 2012, and 2013. These reports range in length from 4 pages to 36 pages, and provide insight into decisions made about Hanford, as well as discussing the advice from the board that is made each year. These reports are invaluable in showcasing environmental justice because they 
are what the Advisory Board wishes to present to the public. It is because of this that the annual reports were chosen to be judged for the project's environmental justice actions.

\section{Literature Review:}

Environmental pollution is a persisting problem that has been around since the industrial era. As society realized that pollutants make human health devolve, some industries moved toward cleaner methods of industrialization, while others moved their polluting to more secluded, less well known, and poorer areas (Jones et al., 2014). A study published in 2015 found that white men predominately cared less about pollution than any other ethnicity or gender (citation). This most likely correlates with the fact that white men are the richest demographic in the United States currently (Barton et al., 2015). Historically, pollution of air, water, and land is significantly higher in areas where citizens of lower class live because they have neither the monetary means to fix the pollutants themselves, nor do they usually have the necessary political voices to make their adverse health situations widely publicized to anyone that could potentially fix the problem or problems (Barton et al., 2015).

The environmental justice movement rose in an effort to combat this historical discrimination (Purdy, 2018). However, evaluating the inclusion of environmental justice is often difficult, due to the case-specific nature of the evaluation. Utilizing different evaluation techniques can be helpful both during and after a project's completion, especially when there are multiple management parties involved (Begg, 2018). In the long run, though, it is necessary for a project's success to include the input of all affected stakeholders, and it generally saves time and money down the road (Begg, 2018). There are several evaluation methods that can incorporate environmental justice. 
Evaluating projects for their ethical and stakeholder inclusion is a difficult task, and there is some literature on the subject that provide general evaluation techniques that are useful for program managers. In 2011, Hornby Zeller Associates, Inc. published a report titled "Guide to Assessment, Planning, \& Evaluation.” This report details not only good planning strategies, but also emphasizes the need for effective evaluation of large-scale projects. This report states that evaluation with special consideration on if and how your community's needs have been met is vital in measuring the success or failure of a project (Hornby Zeller Associates, 2011). They go on to say that evaluation can also function to establish a prevention infrastructure as a project is met with obstacles in the future. As problems arise, evaluation criteria can help form solutions that fit all stakeholders' needs, and assist in ensuring that all departments in collaboration with each other feel that they have adequately participated in discussion and planning (Hornby Zeller Associates, 2011).

This report also details an evaluation method called process evaluation. Process evaluation measures the actions taken towards the completion of a specific goal or goals, and specifies who planned and completed each action, what actions were planned versus actually completed, the timeline of each action, the reasoning for each action, and the specifics of how the action was implemented and how well it met community needs (Hornby Zeller Associates, 2011). This type of evaluation is especially helpful for evaluations that are happening after a project is completed, or after a large portion of it has been completed already. This method of evaluating can not only provide insight into operations that were completed previously, but can help guide decision making in the future.

Another method of evaluation, as described in a report titled "Managing Evaluations: A How-To Guide for Managers and Commissioners of Evaluation" is prospective evaluation. This 
method of evaluation casts an evaluator's thoughts to the future, and has them compare similar programs or methods that have been used in the past and project them onto a current project's needs (Wessal et al., 2015). This method is also helpful for a project that has not reached completion yet - it can help managers evaluate their decision making processes in the past and compare them to successful and completed projects, and make adjustments when necessary in order to stay on the same path to reach their goals. However, this does require a certain expectation of excellence from past completed projects, and may require managers of current projects to do a slight evaluation of the projects they are making comparisons too. This extra work can be discouraging, and may be too daunting of a task for managers that incorporate evaluations frequently into their work.

Another important element of evaluation is the frequency and repetition at which it is done (Wessal et al., 2015). Many projects have specific timelines set for evaluation, and they are usually within the 3-5 year range (Wessal et al., 2015). This frequent evaluation that must be completed on a specific timeframe is an excellent way to continually assess what actions in a project are successful and leading toward the goal of completion, and what actions are redundant and may not be contributing to the achievement of the project goals. This timeline also presents an issue to projects that have already been completed, because there is often not money allocated in a budget for continued monitoring, but it can be a useful tool for projects that span many years (or decades) before completion.

\section{Methods:}

The first phase of this project was to create a rubric-formatted framework that could assist in analyzing the Hanford Advisory Board Reports. This was done by first reading through the Advisory Board Reports and pulling out information that was relevant to the project in order 
to create a rubric that would have the necessary elements to adequately assess the project. This included things like river safety, workers' rights, and stakeholder identification. Each category was created to be both broad yet easily understandable, so that this rubric could be used and read by others. Once this was completed, these general categories were compared with literature surrounding environmental justice, including two pollution mitigation projects that had been completed with environmental justice in mind.

The first project was done in Contra Costa California, and involved clean drinking water rights for a neighborhood that had a high Latino population. The Public Health Division of California utilized a stakeholder identification and public input framework during the entirety of this project that focused on community input and stakeholder identification, and the Healthy Neighborhoods Project Latina Action Team, who had first discovered the drinking water issue, deemed the project an environmentally just one, as the community had been asked for input the entire time and they felt as though their voices were heard (Carillo et al., 2007). The framework that was utilized focused on five main aspects of community input: Identifying, Advocating, Supporting, Consulting, and Involving. This framework was cited as a useful factor in identifying stakeholders as well as involving them (Carillo et al., 2007). The second restoration project that was analyzed was also completed in California, and was a grassroots approach to improving air quality with the goal of lessening health impacts on children with asthma. This framework focused on education, both of the community and of policy makers (Kreger et al., 2011). Although this framework was created before the project was completed and then used to guide policy makers and managers in their actions, the intended outcomes written in the framework still served as a test to the project's success. According to the community, the involvement and knowledge sharing from the start of the project is what determined the achievement of its 
environmental justice inclusion goals, as well as policy makers and community members having the same level of knowledge at all times (Kreger et al., 2011). This was done in order to test the relevance of the categories and to again make sure that they would be adequately evaluating the implementation of environmental justice.

Since each of these mitigation projects were deemed successful by their identified stakeholders, the frameworks that they provided were invaluable in comparing the methods that they chose and the methods that the Hanford Advisory Board has been implementing. Public involvement and correct stakeholder identification seemed to be the two main topics that contributed to successful environmental justice implementation. After that, topics were more specific to individual projects.

The eight categories that were evaluated are as follows: Public Input, Stakeholder Identification, Worker Safety, Surrounding Area Wellbeing, Regional Involvement, Local Involvement, River Protection, and Attempt to Lessen Environmental Impact.

Public Input - Gathering information from the general public and making sure that they have both the knowledge to form opinions and the opportunity to do so is one of the most important ways that stakeholders and their needs can be identified. This includes methods like holding open board room meetings that are open to the public, as well as having online forums available. Also included in this category is the accessibility and understanding of the layman - if knowledge was presented clearly and in such a way that the average citizen could understand it.

Stakeholder Identification - Like public input, stakeholder identification is the baseline for the incorporation of environmental justice. Researching all those that could be affected by an environmental project and making attempts to involve them in the decision making process is a key component in environmental justice. A main aspect of this category was the inclusion of all 
32 board members. Each member represents a separate stakeholder, so the identification of these stakeholders was done at the creation of the Hanford Advisory Board. Not a lot of information is provided in the reports as to how each stakeholder was chosen, but there is a good amount of information on why each member is a good representative for their community.

Worker Safety - The safety of those working on the Hanford site is an issue that has been reported in the past (Lavallee 2016). Although analyzing the lawsuits that have been filed against the management company of Hanford for a violation of worker's rights is beyond the scope of this paper, worker safety is still an important issue that must be examined in every environmental activity. The workforce is one of the most important stakeholders involved in the Hanford project, as they are the ones who will be exposed to the site on a daily basis. Evaluating and prioritizing their safety is essential in the protection of all those involved in Hanford.

Surrounding Area Wellbeing - The Hanford site is surrounded by humans as well as nature. Making sure that the projects being completed on the Hanford site will not impact the area directly around it is essential in protecting the land and those who inhabit it. This category was included after an explicit mention in the 2010 Hanford Advisory Board Report about upkeep of the health of the surrounding area so that the land may be returned to its rightful indigenous owners.

Regional Involvement - A region can be as large as a nation or as small as a county. Since the Hanford project has the potential to affect multiple states, the inclusion of stakeholders in the surrounding regions, and not just the state of Washington, is essential in decision making processes.

Local Involvement - Those who live closest to Hanford are the ones who will feel its project impacts the soonest and the most. Involving the locals and those who have the potential 
to be affected the most by project actions incorporates direct community input, and is an essential stakeholder to consider. This is different from regional involvement in that it is a smaller scale community and involves the stakeholders that would be affected immediately, and not sometime in the vague future.

River Protection - The Hanford site is directly adjacent to the Columbia River, a waterway that provides resources to multiple states and countries (Foundation for Water and Energy Education, 2018). The protection of this river and attempts to lessen impacts on it is essential in protecting all those who utilize those resources, especially since this water body spans internationally as well as across multiple state lines. This category was included mainly because the Hanford Advisory Board mentions the Columbia River and its protection explicitly in a few of their reports.

Attempt to Lessen Environmental Impact - The environment, and nature in general, is a stakeholder that many overlook. Any impacts that the Hanford site may have on the surrounding environment must be planned for, and all attempts to lessen the impact on the surrounding ecosystem will have a positive effect on those who benefit from ecosystem services.

Once the rubric was created, as shown in Table 1, the Hanford Advisory Board Reports were once again analyzed and given a numerical value from 0-3 depending on how they mentioned and/or implemented the various aspects on the rubric. A score of 0 indicated no mention, a score of 1 indicated some mention but no evidence of implementation, a score of 2 indicated some mention with a plan of implementation, and a score of 3 indicated some mention with evidence of implementation. Each advisory board report was analyzed in this way, and then the numbers were added up to get a score out of 192 . This number was then transferred into a percentage to create a more universal understanding of the numerical score. 


\begin{tabular}{|l|l|l|l|l|l|l|l|l|}
\hline & 2007 & 2008 & 2009 & 2010 & 2014 & 2015 & 2016 & 2017 \\
\hline Public Input & & & & & & & & \\
\hline Stakeholder ID & & & & & & & & \\
\hline Worker Safety & & & & & & & & \\
\hline $\begin{array}{l}\text { Surrounding area } \\
\text { wellbeing }\end{array}$ & & & & & & & & \\
\hline Regional Involvement & & & & & & & & \\
\hline Local Involvement & & & & & & & & \\
\hline River Protection & & & & & & & & \\
\hline $\begin{array}{l}\text { Attempt to Lessen } \\
\text { Environmental Impact }\end{array}$ & & & & & & & & \\
\hline
\end{tabular}

Table 1: Blank Environmental Justice rubric with each year of a report from the Hanford Advisory Board

\section{Results:}

In total, the Hanford Nuclear Waste Site Cleanup Project got a score of 133 out of 192, or a score of $69 \%$.

Public Input - The Advisory Board started out strong with advocating methods for public input, including the creation and inclusion of their public commentary committee.

However, 2009 saw less mention of this committee, as well as the year 2017. Most reports had a decent contact information section as a way for the general public to submit comments to the board.

Stakeholder Identification - This section saw solid scores throughout most of the reports simply because of the inclusion of the 32 members of the board and their justification for their positions. However, the more recent reports did not include these in-depth board member reports, and the numbers reflect this. 
Worker Safety - Many earlier reports were very concerned with expressing the need and implementation of worker safety at Hanford. However, as the reports progressed in years, these inclusions got shorter and then, in more recent years, were not included at all.

Surrounding Area Wellbeing - The importance of keeping the natural resources surrounding Hanford was mentioned fairly solidly throughout the yearly reports, however it was not mentioned at all in the year 2015 (the shortest report).

Regional Involvement - The main involvement of the region surrounding Hanford was the involvement of multiple state lines. While this was mentioned explicitly in the years 2007 , 2009, and 2014, it was rarely mentioned in-depth in any other years' report.

Local Involvement - This category scored the lowest across all years, with only one score of 3 in 2014. This year got the highest score because it was a special edition and covered over many of the accomplishments that the advisory board had made over the past 20 years, including their inclusion of local stakeholders. Besides this year, not much local involvement was sought out by the board.

River Protection - This was another one of the strongest categories throughout all of the reports. The board obviously recognized the importance of the Columbia River, and usually had a small section in each report mentioning how they were attempting to preserve its integrity and environmental health.

Attempt to Lessen Environmental Impact - This category also had very high scores throughout the years, although it did dip down once the reports started getting shorter in the year 2015. Much of the advice that the board provided was centered around protecting the environment, especially the groundwater in the area. 
As shown in Table 2, the year 2014 report got the highest score, with only one point missing from a perfect evaluation. The next report from the year 2015 got the lowest score of 9 . The first advisory board report published in 2007 got the second highest score of 20, and the most recent advisory board report published in 2017 go the second lowest score of 10 .

\begin{tabular}{|l|l|l|l|l|l|l|l|l|l|}
\hline & 2007 & 2008 & 2009 & 2010 & 2014 & 2015 & 2016 & 2017 & Avg. \\
\hline Public Input & 3 & 2 & 1 & 3 & 3 & 2 & 2 & 1 & 2.1 \\
\hline Stakeholder ID & 2 & 2 & 2 & 2 & 3 & 2 & 1 & 2 & 2 \\
\hline Worker Safety & 3 & 3 & 2 & 3 & 2 & 1 & 2 & 0 & 2 \\
\hline $\begin{array}{l}\text { Surrounding area } \\
\text { wellbeing }\end{array}$ & 3 & 1 & 2 & 3 & 3 & 0 & 3 & 1 & 2 \\
\hline $\begin{array}{l}\text { Regional Involvement } \\
\text { Local Involvement }\end{array}$ & 3 & 2 & 3 & 1 & 3 & 1 & 1 & 1 & 1.8 \\
\hline $\begin{array}{l}\text { River Protection } \\
\text { Attempt to Lessen } \\
\text { Environmental Impact }\end{array}$ & 3 & 3 & 3 & 3 & 3 & 1 & 3 & 2 & 2.6 \\
\hline & 3 & 3 & 3 & 3 & 3 & 1 & 3 & 2 & 2.6 \\
\hline \begin{tabular}{l} 
Total (/24) \\
\hline
\end{tabular} & 20 & 18 & 17 & 19 & 23 & 9 & 17 & 10 & 1.5 \\
\hline
\end{tabular}

Table 2: Environmental Justice rubric filled out with scores from the Hanford Advisory Board Reports from 2007-2017.

Figure 1 shows that there is no yearly linear trend on how well the reports incorporated environmental justice. However, we do see the two lowest scores in more recent years: 2015 and 2017. 


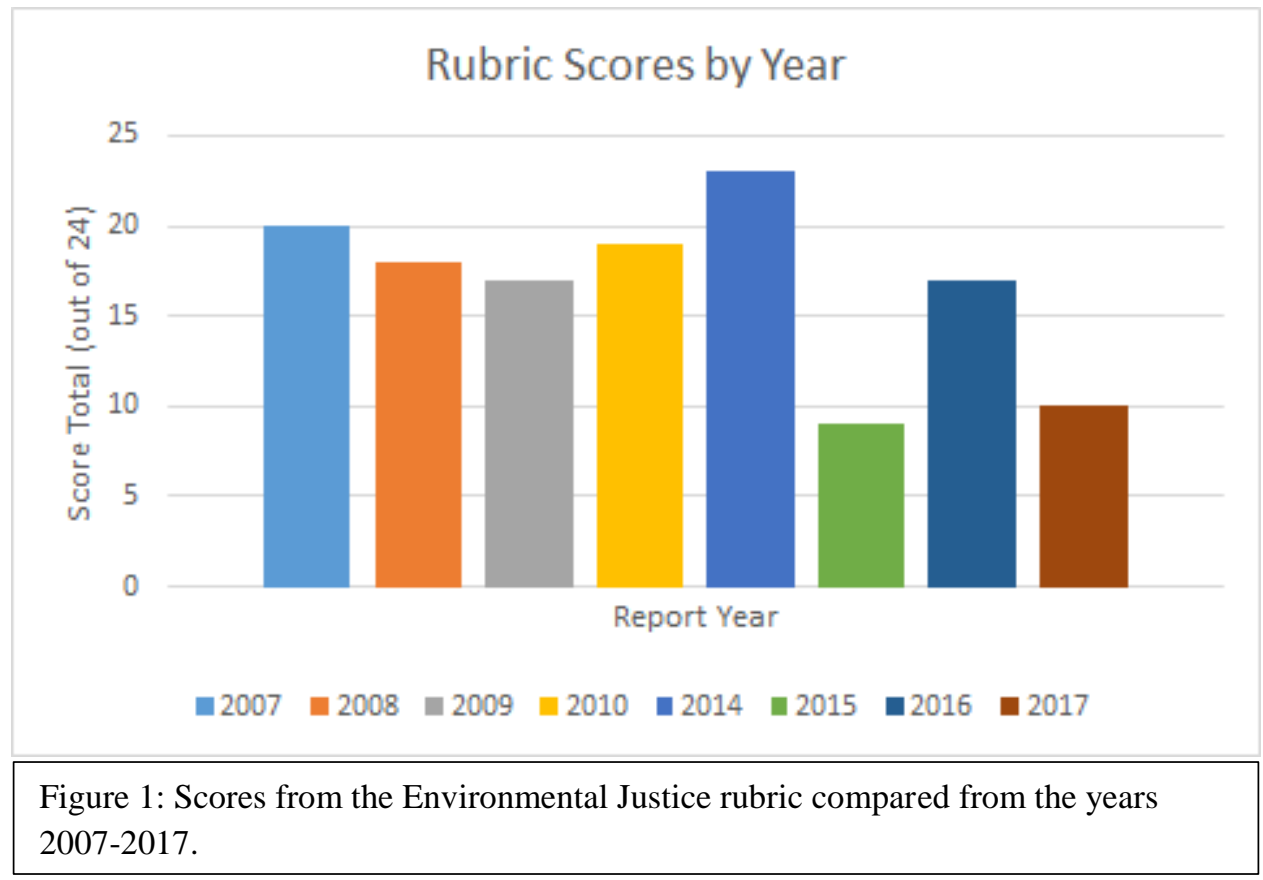

\section{Discussion:}

The averages for each category show that local and regional involvement are where the Hanford Advisory Board needs to improve the most. This can often overlap with public involvement, but it takes more of a concentrated effort to identify who the specific local and regional stakeholders may be, and therefore may be more difficult to address consistently. This is a common theme among environmental projects that have many stakeholders at varying levels; the identification of all who may be affected by a project is difficult and often overlooked (Mansourian et al., 2017). All other categories got between a 2 and a 2.6, which are fairly high scores on average.

The Hanford Cleanup Project has spanned decades worth of time and acres worth of land. It has had to fight budget cuts, leadership switches, and lawsuits, and yet this giant restoration project still managed to receive a score of $69 \%$ on an environmental justice rubric. This is not a perfect score by any means, but it does show progress and attention to social issues. The creation 
of the Hanford Advisory Board in the early 1990s showed that the managers of the Hanford project were taking public and stakeholder input seriously. Additionally, their high scores throughout the years in attempt to lessen environmental impact shows that they are not only paying attention to their stakeholders with a voice, but also to the land and resources that may be affected.

Of course, analyzing only the Hanford Advisory Board reports may give a biased report on how well the project has included environmental justice. These reports were written and published by people who want to display the Hanford project in a favorable light. A more truthful assessment could be taken by factoring in the multiple lawsuits filed by workers of Hanford, and also actual interviews from the community. Reports are useful for quick compilations of information, but they may not be the best tool for assessing the true state of complex social issues.

This initial rubric is meant as a stepping stone for managers to identify how they can be incorporating environmental justice into their works. It is designed in a way that it can be added onto and adjusted for the specifics of an individual project, and the evaluation methods that were used can also be switched around to fit specific project needs. In future implementations of this rubric, it would be beneficial to have multiple unbiased parties assess a project and have an average score become the final representation of the rubric's score. It also may be beneficial to incorporate evidence from non-managerial sources, like members of the community and stakeholders outside of the realm of the agencies in charge. This way, a true compilation of stakeholder opinions can be compiled, and used in continuation steps for managers.

Environmental justice has a variety of definitions, but each one aims for the same goal: to include all stakeholders that may be affected by an environmental project in both decision 
making and planning (Miller-Travis, 2017). It aims to give all organisms a voice: not just humans, but animals, plants, and land as well (Neimanis et al., 2012). Environmental justice is a growing movement, especially in current times, but there is still much work to be done to ensure that it is incorporated in every environmental project, and especially large-scale ones that cross state lines with multiple parties in charge. This rubric is a single step in evaluating large scale environmental projects in their impacts and recognition of all those who are affected by their actions, and may aid in providing guidance to managers as they attempt to rehabilitate the environment while keeping the health and safety of the entire surrounding ecosystem and all who inhabit it in mind. 


\section{References:}

Barton Laws, M., Yeh, Y., Reisner, E., Stone, K., Wang, T., \& Brugge, D. (2015). Gender, Ethnicity and Environmental Risk Perception Revisited: The Importance of Residential Location. Journal Of Community Health, 40(5), 948-955. doi:10.1007/s10900-015-0017-1

Begg, C. (2018). Power, responsibility and justice: a review of local stakeholder participation in European flood risk management. Local Environment, 23(4), 383-397.

doi:10.1080/13549839.2017.1422119

Callahan, C., DeShazo, J. R., \& Kenyon, C. (2011, September 30). Pathways to Environmental Justice: Advancing a Framework for Evaluation. Retrieved from UCLA School of Public Affairs website

Carillo, R., Morgan, M. A., \& Kent, M. (2007, October). Environmental Justice Framework: A Public Health Approach. Retrieved from The Public Health Outreach, Education and Collaboration unit (PHOEC) website: https://cchealth.org/topics/environmental/pdf/ej_framework_article_2007_11.pdf

Executive Order 12898. (1996, February 13). Retrieved from The American Presidency Project website

Foreman, C. H. (2002, January 11). Remarks on Environmental Justice. Retrieved from Brookings website: https://www.brookings.edu/testimonies/remarks-on-environmental-justice/

Hall, M. (2015). History of Environmental Cleanup and Restoration. World Environmental History

Jones, M. R., Diez-Roux, A. V., Hajat, A., Kershaw, K. N., O'Neill, M. S., Guallar, E., \& ... Navas-Acien, A. (2014). Race/Ethnicity, Residential Segregation, and Exposure to Ambient Air Pollution: The Multi-Ethnic Study of Atherosclerosis (MESA). American Journal Of Public Health, 104(11), 2130-2137. doi:10.2105/AJPH.2014.302135

Kreger, M., Sargent, K., Arons, A., Standish, M., \& Brindis, C. D. (2011, December). Creating an Environmental Justice Framework for Policy Change in Childhood Asthma: A Grassroots to Treetops Approach. American Journal of Public Health, 101, 208-216.

Lavelle, P. (2016, November 3). Hanford: Court Rejects Feds' Motion to Dismiss AG Lawsuit Over Worker Safety. Retrieved from Washington State Office of the Attorney General website: www.atg.wa.gov/news/news-releases/hanford-court-rejects-feds-motion-dismiss-ag-lawsuitover-worker-safety

Mansourian, S., Dudley, N., \& Vallauri, D. (2017). Forest Landscape Restoration: Progress in the Last Decade and Remaining Challenge. Ecological Restoration, 35(4), 281-288. 
Miller-Travis, V. (2017). Now Is the Time for Enhancing the Federal Role. Environmental Forum, 34(6), 53

Neimanis, A., Castleden, H., \& Rainham, D. (2012). Examining the place of ecological integrity in environmental justice: A systematic review. Local Environment, 17(3), 349-367. doi:10.1080/13549839.2012.665863

Niles, K. (2014). The Hanford cleanup: What's taking so long?. Bulletin Of The Atomic Scientists, 70(4), 37-48. doi:10.1177/0096340214539115

Palamar, C. R. (2008). The Justice of Ecological Restoration: Environmental History, Health, Ecology, and Justice in the United States. Human Ecology Forum, 15(1), 82-94.

Purdy, J. (2018). The Long Environmental Justice Movement. Ecology Law Quarterly, 44(4), 809-864. doi:10.15779/Z382F7JR1V

Strategic Prevention Framework: Guide to Assessment, Planning, \& Evaluation. (2011). Retrieved from Hornby Zeller Associates, Inc. website: www.maine.gov/dhhs/samhs/osa/pubs/data/2011/GuidetoAssess.Plan.Eval.pdf

The Columbia River Basin. (2018). Retrieved from Foundation for Water \& Energy Education website: fwee.org/environment/what-makes-the-columbia-river-basin-unique-and-how-webenefit/the-columbia-river-basin/

Timpane-Padgham, B. L., Beechie, T., \& Klinger, T. (2017). A systematic review of ecological attributes that confer resilience to climate change in environmental restoration. Plos ONE, 12(3), 1-23. doi:10.1371/journal.pone.0173812

Wessal, A., Khattri, N., \& Roberts, D. (2015). Managing Evaluations: A How-To Guide for Managers and Commissioners of Evaluation (Report 978-1-60244-258-0). Retrieved from Independent Evaluation Group website: ieg.worldbankgroup.org/sites/default/files/Data/reports/ecd_man_evals.pdf 